\title{
Eklemeli İmalat İle Üretilen Esnek Flap Mekanizmasının Tasarımı Ve Yorulma Testi
}

\section{Design and Fatigue Test of Additive Manufactured Compliant Flap Mechanism}

\section{Salih Kaya ${ }^{1^{*}}{ }^{\oplus}$, Tuğberk Güngördü1 ${ }^{\circledR}$, Mert Ali Özel ${ }^{1}[0$}

${ }^{1}$ Bursa Uludağ Üniversitesi Mühendislik Fakültesi Makine Mühendisliği Bölümü, Bursa, TÜRKiYE Sorumlu Yazar / Corresponding Author*: salihkaya.tr@yahoo.com

\author{
Geliș Tarihi / Received: 29.11.2020 Araștırma Makalesi/Research Article \\ Kabul Tarihi / Accepted: 09.02.2021 DOI:10.21205/deufmd.2021236922 \\ Atıfsekli/How to cite: KAYA S., GÜNGÖRDÜ T., ÖZEL M.A. (2021). Eklemeli İmalat İle Üretilen Esnek Flap Mekanizmasının Tasarımı Ve \\ Yorulma Testi. DEÜFMD 23(69), 951-960.
}

$\ddot{0} \mathbf{z}$

Bu çalışmada Insansız Hava Aracına (IHA) ait esnek flap mekanizması tasarlanmış ve model IHA için üretilmistir. Bu sayede, parça sayısında azalma ve mafsal kullanılmaması sebebiyle mafsallar içerisindeki iç sürtünmeler gibi problemler giderilmiştir. Mekanizmanın çalışma koşullarındaki davranışlarının hesaplanması için bu çalışmada eşlenik rijit cisim metodu yardımıyla doğrusal bir model geliștirilmiştir. Geliştirilen esnek mekanizma, geleneksel mekanizmaya göre motordan talep ettiği toplam tork değerinin yaklaşık üç kat arttığı görülmüștür. Eklemeli imalat yöntemiyle Semiflex plastik malzemeden üretilen bu mekanizmanın yorulma analiz davranıșlarının gözlemlenmesi için test düzeneği tasarlanmış ve 717727 çevrime kadar hasar meydana gelmeden çalışmıştır. Yapılan çalışma literatürde eksik olan, eklemeli imalat ile Semiflex plastik malzemeden üretilmiş esnek flap mekanizmasının kinetik ve yorulma performansları hakkında bilgiler sunarak yeni çalışmalara referans olacağı düşünülmektedir.

Anahtar Kelimeler: Esnek mekanizma, dört uzuvlu mekanizmasl, eklemeli imalat.

\begin{abstract}
In this study, the compliant four-bar flap mechanism was developed for the Unmanned Aerial Vehicle (UAV). Therefore, several problems have been avoided such as a decrease in the number of parts and eliminated internal friction in the joints problems. A linear model was developed with the help of the pseudo rigid body method to calculate the behavior of the mechanism under operating conditions. The kinetic performance of the compliant four-bar mechanism was compared with the conventional fourbar mechanism. It was observed that the total torque demand of the compliant flap mechanism increased. The test setup was designed to observe the fatigue analysis behavior of this mechanism which produced by the additive manufacturing method. Consequently, the compliant mechanism was reached the 717727 operating cycles. The study is thought to be a reference to new studies by presenting information about the kinetic and fatigue performances of the compliant flap mechanism made of Semiflex plastic material.
\end{abstract}

Keywords: Compliant mechanism, four-bar mechanism, additive manufacturing. 


\section{Giriş}

İnsansız Hava Araçları (İHA) teknolojileri geliştirme çalıșmaları son zamanlarda önem kazanmıştır. Küçük hacimdeki insansız hava aracı platformlarının geliștirilmesiyle düșük kütleli kargo taşıma, gözetleme, haritalama vb. sivil ya da askeri görevleri icra edilebilmektedirler. Hava aracında kullanılan mekanizmalara ait mekanik parçaların ağırlı̆̆ının azaltılması ile hava aracının faydalı yük kapasitesi arttırılıp uçuş süresi ve menzil değerleri iyileştirilebilmektedir. Hava aracında kullanılan mekanik parçalardan temel olarak beklenilen, görevini emniyetle gerçekleştirmesi, az bakıma ihtiyaç duyması, uzun ömürlü olarak çalışabilmesi ve bu görevi mümkün olacak en az kütle kullanarak gerçekleștirilmesidir.

Mekanizma, hareketi, kuvveti veya enerjiyi aktarmak veya dönüştürmek için kullanılan bir sistemdir [1]. Geleneksel sert gövde mekanizmaları, mafsal olarak tabir edilen hareketli bağlantılarla bağlanan uzuvlardan oluşur. Esnek mekanizmalar rijit mekanizmalar gibi hareket, kuvvet veya enerji iletimi ya da dönüşümü sağlarlar. Rijit kol mekanizmalarından farkı ise esnek mekanizmalar hareketliliğini oynar eklemlerin yer değişiminden değil esnek elemanlarının șekil değişiminden sağlarlar [2].

Hava araçlarında flaplar genel olarak hava freni görevi yapmaktadırlar. Bunun yanında, sabit kanatlı hava aracının kısa sürede kalkıș yapmasına ve kısa mesafede durmasını sağlarlar. Flaplerin hareketinin kontrolünde farklı tipte mekanizmalar tercih edilebilmektedir. Bunun yanında tercih edilen mekanizmalardan birisi de geleneksel dört çubuk mekanizmasıdır. Esnek mekanizmanın dört çubuk mekanizma yapısına sahip flap mekanizmasına uyarlanmasıyla farklı avantajlar elde edilmektedir. $\mathrm{Bu}$ avantajlar, mekanizma ağırlıklarının azaltılması, mafsallar arası boșluklardan kaynaklı titreșim ve gürültünün oluşmasina engel olunması, mafsalların bakım ihtiyacının azaltılması, parça sayısı azaltılarak üretim ve montaj süresinin azaltılması olarak belirtilebilir. Esnek mekanizmaların, daha az parçaya sahip olmasıyla eşlenik geleneksel mekanizma versiyonundan daha hafif olabilmekte, montaj süresini kısaltmakta, parça takibini ve üretim sürelerini azaltmaktadır. Daha az hareketli parça sebebiyle, yağlanma ve bakım ihtiyacı en aza indirilmiş olur [3].

Esnek mekanizmalar üzerinde yapılan çalışmalar son yıllarda büyük bir artış göstermiștir [2,4]. Esnek mekanizmaların geleneksel mekanizmalara göre yukarıda belirtilen özelliklere sahip olmasına ek olarak, son yıllardaki artışın sebebi eş zamanlı olarak eklemeli imalat teknolojisinin gelișmesi ve bu sebeple imalatı zor mekanizmaların üretilmesine imkan tanınmasıdır [2].

Esnek mekanizmaların bu avantajlarının yanında dikkate alınması gereken yorulma problemi ve matematik modellemenin zorluğu gibi dezavantajlara sahiptir [5]. Esnek mekanizmalarda, şekil değiștiren bölgelerde yorulma kaçınılmazdır. $\mathrm{Bu}$ sebeple, mekanizmanın kullanım yerine göre yorulma dayanımı arttırılacak şekilde tasarımı yapılmalı ve malzemesi bu durum dikkate alınarak seçilmelidir.

Esnek mekanizmaların tasarım aşamasında karşılaşılan birçok soruna yönelik farklı metotlar geliștirilmiștir. Eşlenik rijit cisim modeli esnek mekanizmaların analiz ve tasarımında tercih edilen doğrusal modellerden birisidir. Elemanların burulma yayları ile bağlanıp simüle edildiği bu metot nümerik yöntemlerle bilgisayar destekli ortamlarda yapılan sonuçlara yakın değerler vererek doğrulanmıștır [6]. Nelson ve ark. [7], dört çubuk mekanizması ile kontrol edilen flaplarda iki esnek bağlantı ile analiz yapılmıștır. Erkaya ve Uzmay [8], esnek mekanizmaların davranışlarından doğan hareketin makro ve mikro birçok uygulamadaki performanslarını araștırmıștır. Doğrusal olmayan davranışlar elastika teorisinden faydalanılarak çözülmüştür. Gerdes ve ark. [9] çalışmalarında, esnek mekanizmaların konum hassasiyetlerini incelemişlerdir. Eşlenik rijit cisim modelinin esnek uzuv tasarımında kullanılan bir metot olduğu ve çeșitli mekanizmalara yapılan benzetimleri açıklanmıştır. Sonuçlar sonlu elemanlar yöntemi kullanılarak karşılaştırılmıştır [9]. Bir katlama sanatı olan origami, esnek mekanizmaların basit örnekleri olarak tanımlanabilir. Katlama teknikleri esnek uzuv bölgelerine uyarlanarak montaj, maliyet ve sürtünmelerin azaltılması hedeflenmiştir [3]. Bir diğer çalışmada [10], esnek mekanizmaların statik ve dinamik analizinde matris yer değiștirme yöntemi esas 


\section{DEÜ FMD 23(69), 951-960, 2021}

alınarak analitik bir yöntemle çözülüp sonuçların ANSYS sonlu elemanlar yazılımı ile karşılaştırılması incelenmiştir. Sonuçlarda yüzde 5 'den daha az hata oranı ile doğruluk yakalanmıştır. Esnek mekanizmalar mafsallarda meydana gelen sürtünmeyi azaltmakta ve böylece sürtünmeyi yenmeye harcanan enerjiyi en aza indirmektedir [11]. Hava araçlarında kanat yapıları uçuş performansını etkilemektedir. Dolayısıyla kanat yapılarının esnek olmasının birçok faydası vardır. Yue ve Zhang [12], esnek kanat tasarımında çıkabilecek problemleri incelemișlerdir.

Günümüzde eklemeli imalat ile üretilen parçaların büyük çoğunluğu plastik malzemeden oluşmaktadır. Esnek mekanizmalar, çalışma koşuluna uygun olması durumunda plastik malzemeden üretilebilmektedirler [13]. $\mathrm{Bu}$ avantajları sayesinde, üretim adedi az parçalarda eklemeli imalat yöntemi tercih edilmesiyle üretim maliyetleri azaltılabilmektedir. Küçük ebatlı İHA platformlarında, birçok mekanik parçada plastik malzeme tercih edilebilmektedir. Esnek mekanizmaların eklemeli imalat ile plastik malzemeden üretilmesi ve analizleri hakkında literatürde çok az çalışma bulunmaktadır. Bunun temel sebebinin, eklemeli imalat teknolojisinin son zamanlarda yaygınlaşması ve özellikle esnek uzuvlara uygun plastik filamentlerin son yıllarda geliştirilmiş olduğu düşünülmektedir. Yapılan bu çalışmanın literatüre en önemli katkılarından birisi, esnek flap mekanizmasının eklemeli imalat ile üretilmesi ve test çalışmaları ile doğrulanması yapılarak literatüre katkı sağlanması amaçlanmaktadır. Çalışmada esnek mekanizmanın, özellikle esneme kabiliyeti iyi olan Semiflex plastik filament kullanılarak üc boyutlu yazıcıda üretilmiştir. $\mathrm{Bu}$ üretim yönteminin kullanımı ile esnek ve karıșık yapıdaki parçalar ile küçük yapıdaki parçaların üretimi gerçekleştirilebilmektedir. Ayrıca bu çalışmada, esnek mekanizmanın, geleneksel rijit gövdeli mekanizmalara göre çalışma koşulu altındaki davranıșlarının karșılaștırılabilmesi için mekanizmaların hareket denklemlerini içeren matematik modeller oluşturulmuştur. Matematik modeller, MATLAB programı yardımıyla çözdürülmüş ve sonuçlar tartışılmıștır. Esnek mekanizma üretimi yapıldıktan sonra, tasarlanan ve üretilen yorulma test sistemi yardımıyla yorulma testine tabii tutulmuş ve 717727 çevrime kadar hasar oluşmadan çalışabilmiştir. Çalışma sonucunda elde edilen çıtılar, esnek mekanizmaların avantajlarını doğrulamış ve plastik malzemeden eklemeli imalat yöntemiyle üretilip kullanılmasının uygun olduğu sonucuna varılmıștır. $\mathrm{Bu}$ avantajlarının yanında, esnek mekanizmanın tork talebini yaklaşık üç kat arttırması sebebiyle tahrik motoru gücünü arttırdığı görülmüștür.

\section{Materyal ve Metot}

\subsection{Esnek Mekanizmanın Matematik Modeli}

Esnek mekanizmanın tasarımında referans alınan 1,35 kilogram kalkış ağırlığına sahip İHA modeli Şekil 1'de tanımlanmıștır. Tasarlanan esnek mekanizma, flap görevini yerine getirmesi ve flapin maksimum açılma açısı olan $26^{\circ}$ değerini sağlaması beklenmektedir. Bunun yanında, bazı küçük ebatlı İHA modellerinde performansa olumsuz etkilerinden ötürü flapler tercih edilmemekte ve sadece aileron kullanılmaktadır [14]. Literatürden bilindiği üzere [15], aileron mekanizmasının genel çalıșma prensibi flap mekanizmasıyla benzerlik göstermekte olup, bu çalıșma kapsamında geliştirilen model yardımıyla uygun tasarım değișikleriyle flap mekanizması için geliștirilen esnek mekanizma aileron mekanizmaları içinde kullanılabilmektedir.

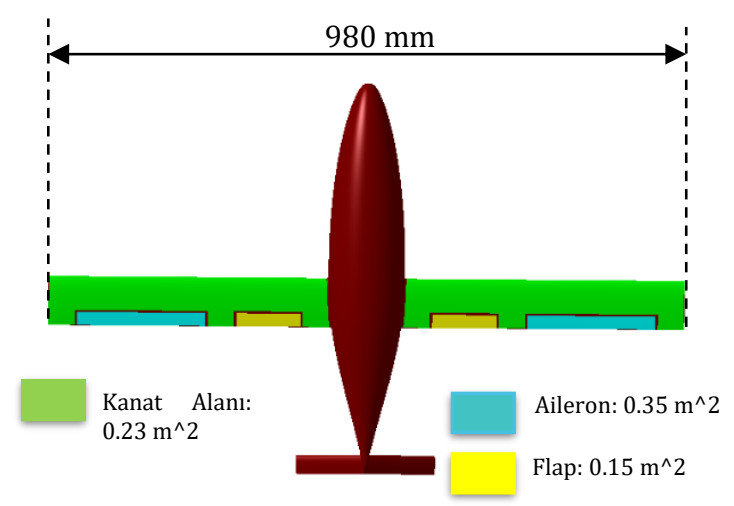

Şekil 1. Referans İHA Özellikleri.

Flap mekanizması belirli açı ile açlıp kapanması sonucunda taşıma kuvveti ve kısmen de sürüklemeyi artırır. Günümüzde var olan uçakların flap mekanizmasını incelediğimizde, tercih edilen mekanizma tiplerinden birisi geleneksel dört çubuk mekanizmasıdır. Şekil 
DEÜ FMD 23(69), 951-960, 2021

2'de görüldüğü üzere, model uçak referans alınarak geleneksel dört çubuk mekanizması tasarlanmıştır. Mekanizmanın ölçüleri Tablo 1'de paylaşılmıştır.

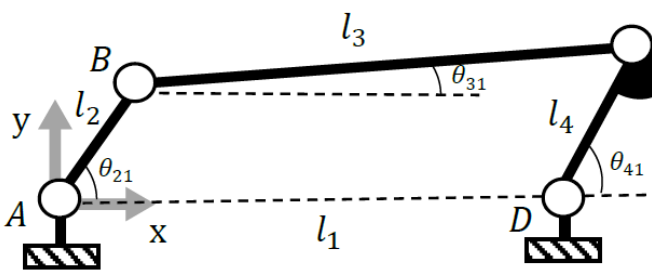

Şekil 2. Geleneksel dört uzuvlu mekanizma

Dört uzuvlu mekanizmanın kapalı döngü denklemi Denklem 1'de tanımlanmıştır.

$\overrightarrow{A B}+\overrightarrow{B C}=\overrightarrow{A D}+\overrightarrow{D C}$

Kapalı döngü denklemi yardımıyla elde edilen vektörler kompleks sayılar metoduyla Denklem 2 'de görüldüğü gibi ifade edilmektedir.

$l_{2} e^{i \theta_{21}}+l_{3} e^{i \theta_{31}}=l_{1} e^{i \theta_{11}}+l_{4} e^{i \theta_{41}}$

Tek serbestlik dereceli dört uzuvlu mekanizmada, $\mathrm{AB}$ uzvunun açısı $\theta_{21}$ elektrikli servo motoru yardımıyla kontrol edilmektedir. Bu kontrole bağlı olarak, $\theta_{31}$ ve $\theta_{41}$ açıları ekler bölümünde tanımlanan Freudeinstein [16] denklemi yardımıyla hesaplanabilir. Geleneksel dört uzuvlu mekanizma ile eşleniği olan esnek mekanizmaların tork, açısal hız ve güç değerleri üzerinden kıyaslanabilmesi için Denklem 3'te görüldüğü üzere kapalı formda verilen mekanizmanın hareket denklemine ihtiyaç duyulmaktadır.

$T(\theta) \ddot{\theta}+V(\theta, \dot{\theta})=M_{\theta}$

Burada, $T(\theta)$ konuma bağlı değişkenleri içeren açısal ivmenin $\ddot{\theta}$ katsayısı, $V(\theta, \dot{\theta})$ ifadesi ise konum ve hıza bağlı terimler, $M_{\theta}$ ise mekanizmaya uygulanan diș moment ifadelerini içermektedir. $\mathrm{Bu}$ ifadelerin detayları ekler bölümünde tanımlanmıștır.

Geleneksel dört çubuk mekanizması yerine ikame etmek için tasarlanan esnek dört çubuk mekanizması flap mekanizmasına uyarlanmasıyla, özgün tasarım sayesinde mekanizma ağırlıklarının azaltılması, mafsallar arası boşluklardan kaynaklı titreșim ve gürültünün oluşmasına engel olunması, mafsalların bakım ihtiyacının azaltılması, parça sayısı azaltılarak üretim ve montaj süresinin azaltılması amaçlanmaktadır.

Tablo 1. Geleneksel dört uzuvlu mekanizma özellikleri.

\begin{tabular}{|c|c|c|c|}
\hline $\begin{array}{l}\text { AD Uzvu } \\
\text { Uzunluğu } \\
\mathbf{l}_{\mathbf{1}}\end{array}$ & $60 \mathrm{~mm}$ & $\begin{array}{c}\text { Esnek } \\
\text { Bölgenin } \\
\text { Kesit } \\
\text { Genişliği b }\end{array}$ & $1.5 \mathrm{~mm}$ \\
\hline $\begin{array}{c}\text { AB Uzvu } \\
\text { Uzunluğu } \\
\mathbf{1}_{\mathbf{2}}\end{array}$ & $10 \mathrm{~mm}$ & $\begin{array}{l}\text { Esnek } \\
\text { Bölgenin } \\
\text { Kesit } \\
\text { Uzunluğu h }\end{array}$ & $3 \mathrm{~mm}$ \\
\hline $\begin{array}{c}\text { BC Uzvu } \\
\text { Uzunluğu } \\
\mathbf{l}_{3}\end{array}$ & $65 \mathrm{~mm}$ & $\begin{array}{l}\text { AB Uzvunun } \\
\text { Kütle Ataleti } \\
\mathrm{I}_{2}\end{array}$ & $\begin{array}{l}1.11 \times 10^{-9} \\
\mathrm{kgm}^{2}\end{array}$ \\
\hline $\begin{array}{l}\text { CD Uzvu } \\
\text { Uzunluğu } \\
\mathbf{1}_{\mathbf{4}}\end{array}$ & $15 \mathrm{~mm}$ & $\begin{array}{l}\text { BC Uzvunun } \\
\text { Kütle Ataleti } \\
\mathrm{I}_{3}\end{array}$ & $\begin{array}{l}1.22 \times 10^{-9} \\
\mathrm{kgm}^{2}\end{array}$ \\
\hline $\begin{array}{l}\text { CD } \\
\text { Uzvunun } \\
\text { Kütle } \\
\text { Ataleti } \mathbf{I}_{\mathbf{4}}\end{array}$ & $\begin{array}{c}7.98 \times 10^{-9} \\
\mathrm{kgm}^{2}\end{array}$ & $\begin{array}{l}\text { AB Uzvunun } \\
\text { Kütlesi m } \\
2\end{array}$ & $\begin{array}{c}3.154 \times 10^{-4} \\
\mathrm{~kg}\end{array}$ \\
\hline $\begin{array}{c}\text { BC } \\
\text { Uzvunun } \\
\text { Kütlesi } \mathbf{m}_{\mathbf{3}}\end{array}$ & $\begin{array}{c}6.48 \times 10^{-5} \\
\mathrm{~kg}\end{array}$ & $\begin{array}{l}\text { CD Uzvunun } \\
\text { Kütlesi m } 4\end{array}$ & $\begin{array}{c}3.487 \times 10^{-5} \\
\mathrm{~kg}\end{array}$ \\
\hline
\end{tabular}

Esnek mekanizmanın matematik modeli Şekil 3'de görülen eşlenik rijit cisim modeli ile yapılmıştır. Bu metot esnek mekanizmaların, rijit cisimlerin kinetik analiz metotlarına benzetimi prensibine dayanır. Analizlerde, kinematik hareketler ve gerilmeler eşlenik model vasıtasıyla hızlı ve verimli bir şekilde saptanabilmektedir. İlk tasarım aşamalarında, eşlenik rijit-cisim modeli tasarım hedeflerini karşılamak için farklı denemeleri, hızlı ve verimli bir şekilde uygulamaya olanak tanımaktadır. Amacına uygun bir ön tasarım yapıldıktan sonra, model daha sonraki aşamada daha detaylı doğrusal olmayan sonlu elemanlar analizleri ile iyileștirilebilmektedir. Eşlenik modeli kullanılarak oluşturulan tasarım metotlarındaki gelişmeler önemli bir araştırma konusudur. Eşlenik model, her esnek parça için bir şekil değiștirme yörüngesini ve kuvvet-deformasyon ilișkisini ön görmektedir. Model, birbirine burulma yayı ile bağlanmış rijit parçalardan oluşur. 


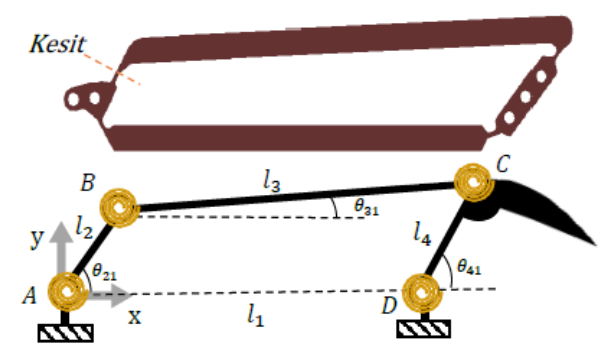

Şekil 3. Esnek mekanizmanın eşlenik rijit cisim modeli

Esnek kısmın hassas olarak kuvvet-deformasyon ilişskisini tanımlayabilmek için burulma yayları sisteme eklenmektedir. Eşlenik modellerin en önemli noktası, pimli bağlantının nerede olacağı ve yay sabitinin değerinin belirlenmesidir [2] Eşlenik rijit cisim yöntemi gereği, esnek mekanizmada mafsalların yerini burulma yayları alacaktır. Burulma yayı sabiti $K$ Denklem 4 yardımıyla bulunabilir. Bu ifadenin detayı ekler bölümünde sunulmuştur.

$$
K=\frac{E I_{k}}{l_{k}}=\frac{E b h^{3}}{12 l_{k}}
$$

Burada E malzemenin elastisite modülü, $I_{k}$ esnek bölgenin alan atalet momenti ve $l_{k}$ esnek bölgenin uzunluğudur. Dikdörtgen kesite sahip geometri için $b$ genişlik ve $h$ yüksekliktir. Esnek mekanizma, eklemeli imalatta \%100 doluluk oranıyla üretilmiştir. Literatürdeki referans çalışmaya [15] istinaden malzeme davranışı homojen kabul edilmiştir. Bu kabulün sonuçlara olan etkisi ileriki çalışmalarda incelenmesi hedeflenmiştir. Seçilen semiflex malzemenin yoğunluğu $\quad 1221.6 \quad \mathrm{~kg} / \mathrm{m}^{3} \quad$ olarak tanımlanmaktadır [17]. Șekil 2 referans alındığında, burulma yayı noktaları olan A, B, C ve $\mathrm{D}$ noktalarındaki deplasmanla birlikte oluşan burulma yayı momentleri sirasiyla $T_{K_{1}}, T_{K_{2}}, T_{K_{3}}$ ve $T_{K_{4}}$, Denklem 5 ile Denklem 8 arasında tanımlanmıştır.

$$
\begin{aligned}
& T_{K_{1}}=-K_{1}\left(\theta_{21}-\theta_{20}\right) \\
& T_{K_{2}}=-K_{2}\left[\left(\theta_{31}-\theta_{30}\right)-\left(\theta_{21}-\theta_{20}\right)\right] \\
& T_{K_{3}}=-K_{3}\left[\left(\theta_{41}-\theta_{40}\right)-\left(\theta_{31}-\theta_{30}\right)\right] \\
& T_{K_{4}}=-K_{4}\left(\theta_{41}-\theta_{40}\right)
\end{aligned}
$$

Burada $K_{1}, K_{2}, K_{3}$ ve $K_{4}$ sirasiyla A, B, C ve D noktalarındaki burulma yaylarının rijitliğidir. Tüm burulma yayları eşit rijitliğe sahiptir ve Denklem 4 yardımıyla hesaplanabilmektedir. $\theta_{20}, \theta_{30}$, ve $\theta_{40}$ ise 2,3 ve 4 nolu uzuvların eşlenik esnek mekanizmadaki başlangıç konumlarıdır.

Eşlenik esnek mekanizmanın, Denklem 3'te elde edilen geleneksel dört uzuvlu mekanizma gibi hareket denkleminin elde edilebilmesi için, $\mathrm{AB}$ uzvuna indirgenmiş burulma yayı momentleri toplamının $T_{\text {in }}$ diferansiyel formda elde edilmesi gerekmektedir. Bu ifadenin elde edilebilmesi için Denklem 9'da en genel haliyle tanımlanan Virtüel İşler Prensibi kullanılarak Denklem 10 bulunabilmektedir.

$\partial U=0$

$$
\begin{aligned}
T_{i n} \partial \theta_{2}+T_{K_{1}} \partial \theta_{2}+ & T_{K_{2}}\left(\partial \theta_{3}-\partial \theta_{2}\right) \\
& +T_{K_{3}}\left(\partial \theta_{4}-\partial \theta_{3}\right) \\
& +T_{K_{4}} \partial \theta_{4}=0
\end{aligned}
$$

Elde edilen denklemin, $\theta_{2}$ bağlı ifadesi için Denklem 11'de tanımlanan ön hazırlıkların yapılması gerekmektedir. Mekanizma tek serbestlik dereceli olması sebebiyle diğer açı değerleri $\theta_{2}$ 'ye bağlı bir fonksiyon olarak tanımlanabilir.

$\theta_{3}=f_{3}\left(\theta_{2}\right)$

$\theta_{4}=f_{4}\left(\theta_{2}\right)$

$d \theta_{3}=\frac{d f_{3}}{d \theta_{2}} d \theta_{2} \rightarrow \partial \theta_{3}=\frac{d \theta_{3}}{d \theta_{2}} \partial \theta_{2}$

$d \theta_{4}=\frac{d f_{4}}{d \theta_{2}} d \theta_{2} \rightarrow \partial \theta_{4}=\frac{d \theta_{4}}{d \theta_{2}} \partial \theta_{2}$

Denklem 11 yardımıyla, Denklem $10 \quad \partial \theta_{2}$ parantezine alınarak Denklem 12'de görüldüğü gibi sadeleștirilmiş hali elde edilmektedir ve denklem içerisindeki diferansiyel ifadelerin tanımı ekler bölümünde yapılmıştır.

$$
\begin{aligned}
& T_{\text {in }}=K_{1}\left(\theta_{2}-\theta_{20}\right) \\
& +K_{2}\left[\left(\theta_{3}-\theta_{30}\right)-\left(\theta_{2}-\theta_{20}\right)\right]\left(\frac{d \theta_{3}}{d \theta_{2}}-1\right) \\
& +K_{3}\left[\left(\theta_{4}-\theta_{40}\right)-\left(\theta_{3}-\theta_{30}\right)\right]\left(\frac{d \theta_{4}}{d \theta_{2}}-\frac{d \theta_{3}}{d \theta_{2}}\right) \\
& +K_{4}\left(\theta_{4}-\theta_{40}\right)\left(\frac{d \theta_{4}}{d \theta_{2}}\right)
\end{aligned}
$$

\subsection{Yorulma Testi Düzeneği}

Eklemeli imalat yöntemi ile üretilen esnek mekanizmanın yorulma dayanımı yapılacak test ile incelenecektir. Mekanizmanın motor 
DEÜ FMD 23(69), 951-960, 2021

elemanından gelen tahrik hareketine bağlı olarak yaptığı hareketin çevrim sayısı, yapılan yorulma testi ile incelenecektir. Esnek mekanizmada $\mathrm{AB}$ uzvunun $26^{\circ}$ açısal hareketinin testinin yapılabilmesi için, tarama açısı $26^{\circ}$ olan geleneksel dört uzuvlu mekanizma tasarlanarak eklemeli imalat yöntemi ile üretilmiştir. Mekanizmaya gerekli tahriği vermek için 60 dev/dak sabit devirde dönen DC elektrik motoru kullanılmıştır. İncelenen eşlenik esnek mekanizma, eklemeli imalat yardımıyla Semiflex filament kullanılarak üretilmiştir. Esnek mekanizma, salınım hareketini yapabilmesi için deney düzeneği için üretilen geleneksel dört uzuvlu mekanizmanın sarkaç uzvuna kayma ve dönme hareketine imkan tanıyan iki serbestlik dereceli mafsal ile bağlanmıştır. Esnek mekanizmanın yorulma değerinin hesabı için elektronik sayaç eklenmiştir. Elektronik sayaç, mekanizmanın her bir salınım hareketini sayabilmektedir. Geliştirilen deney düzeneği, Şekil 4'te gösterilmiştir.

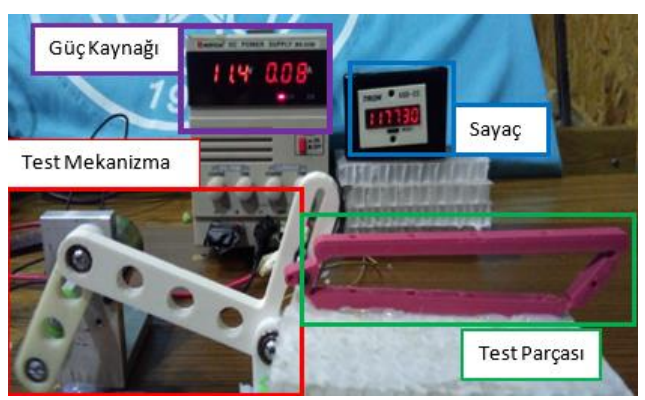

Şekil 4. Yorulma test düzeneği

\section{Bulgular}

Geliștirilen esnek mekanizmanın kinetik performansları, elde edilen hareket denklemleri kullanılarak oluşturulan matematik modelin çıktılarıyla kıyaslanabilecektir. Matematik model ve yapılan yorulma dayanımı testinde, mekanizmanın gerçek çalışma koşulu altından flap kanadından gelen aerodinamik direnç kuvvetleri hesaplara dahil edilmemiştir. Kıyaslanan her iki mekanizma, başlangıç hızlanmasının ardından sabit $60 \mathrm{dev} / \mathrm{dak}$ hızla dönmesi amaçlanmaktadır. Şekil 5'te görüldüğü üzere mekanizmanın küçük ebatlı ve hafif olması sebebiyle hız değerindeki dalgalanmalar 0.001 dev/dak mertebelerindedir. Esnek mekanizmanın, referans geleneksel dört uzuvlu eşleniğine göre hız değerinde daha fazla dalgalanma görülmesi, esnek uzuvların şekil değiştirmeleri neticesinde burulma yayı gibi davranarak enerji depolamasıdır. Bu enerjisini, mekanizmanın tersine hareketine katkl sağlayacak şekilde olmasıla açılanabilmektedir. $\mathrm{Bu}$ nedenle, esnek bölgelerde biriken değişken enerji mekanizmanın tahriğini sağlayan motor elemanının hız değerinde dalgalanmalara sebebiyet olmaktadır. Bu dalgalanmalar, sisteme eklenecek bir volan ile azaltılabilir. Bunun yanında, dalgalanma derecesi cüzi miktarda olması hasebiyle geliștirilen sistem için volan elemana gereksinim duyulmamıștır.

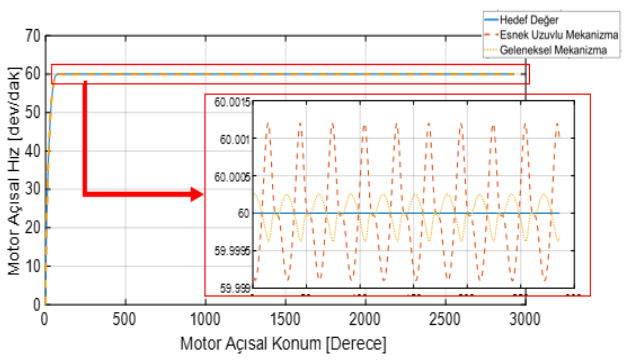

Şekil 5. Motor açısal hız değişimi

Şekil 6'da mekanizmanın 10 turluk tekrarı altında motor elemanının tork değerlerindeki değişimin her iki mekanizma için sunulmuştur. Esnek mekanizmada, burulma yayı gibi davranan esnek bölgelerin şekil değiştirilebilmesi için yaklaşık üç kat daha fazla moment değerine ihtiyaç duyulmaktadır. Esnek mekanizmalar, geleneksel rijit uzuvlu birbirine mafsalla bağlanmıș mekanizmalara göre daha yüksek tork gereksinimi duymaktadırlar. Bunun yanında, esnek elemanlarda geri çağırıcı moment oluşturmaları sayesinde bir çevrimdeki hareketlerinin bir kısminda bu moment kullanılabilir.

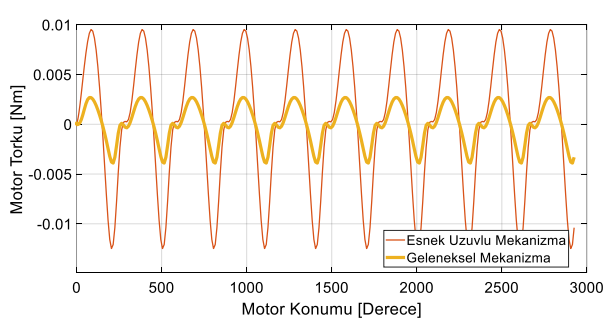

Şekil 6. Motor torku değișim

Şekil 6'da elde edilen sonuca istinaden, esnek mekanizmanın hareketi esnasındaki güç 
gereksinimi geleneksel eşlenik mekanizmaya göre 3 kat daha fazla olduğu Şekil 7'de görülmektedir. Esnek mekanizmaların önemli avantajlarının yanında, daha yüksek tork ve güç gereksinimi duyması motor elemanın tercihinde dezavantaj oluşturmaktadır.

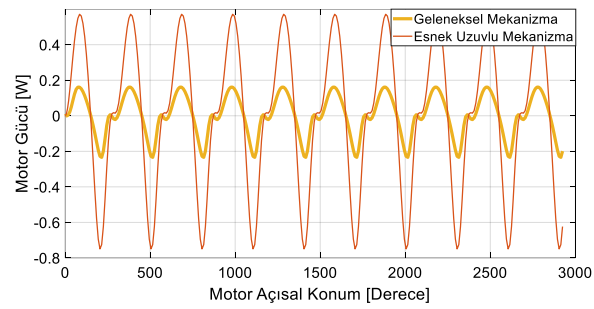

Şekil 7. Motor gücü değişimi

Yapılan test düzeneği ile birlikte Semiflex filament kullanılarak üretilen eşlenik esnek mekanizmanın yorulma dayanımı testi gerçekleștirilmiștir. Șekil 8' de görüldüğü gibi, bu test ile esnek mekanizma yaklaşık 717727 çevrim sayısına kadar hasara uğramadan ulaşmıștır.

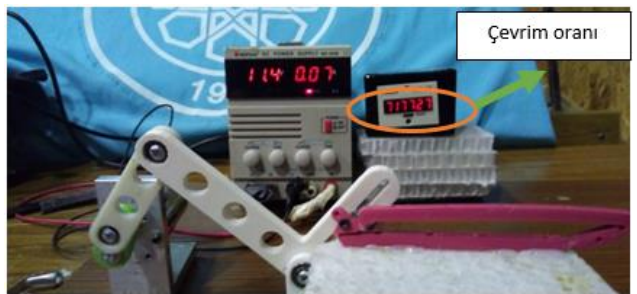

Şekil 8. Yorulma testi sonucu

Şekil 9'da görüldüğü üzere, esnek mekanizma referans model uçağın kanadına montajlanmıştır. Geliştirilen esnek mekanizma, $26^{\circ}$ tarama açısı değerine sahip flap hareketini bașarıyla gerçekleștirmektedir. Flapin bu hareketi neticesinde, kanadın ön yüzey alanını yaklaşık $0.065 \mathrm{~m}^{2}$ artırmaktadır.

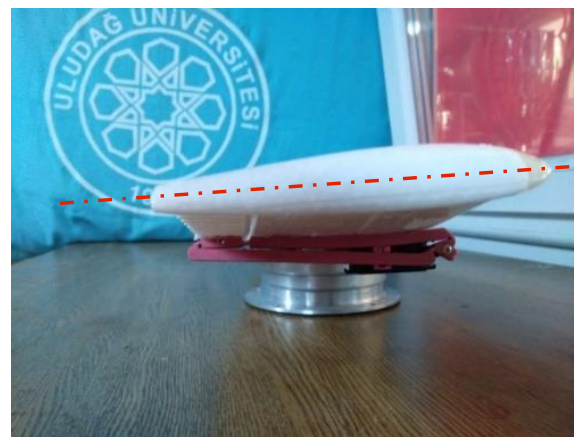

$0^{\circ}$ Pozisyonu

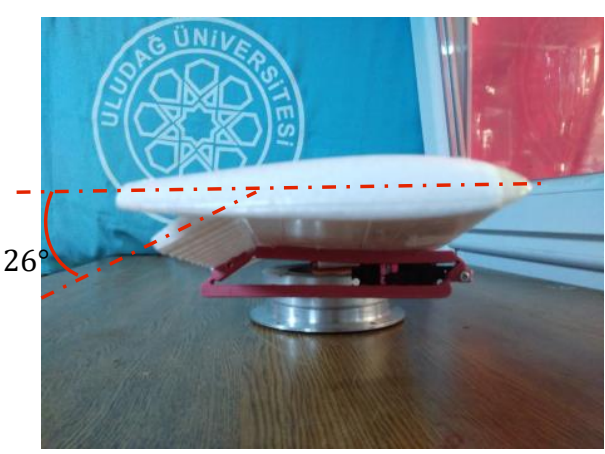

$26^{\circ}$ Pozisyonu

Şekil 9. Esnek mekanizmanın montajı

\section{Tartışma ve Sonuç}

$\mathrm{Bu}$ çalışmada, referans uçak modeline ait flap mekanizmasının eşlenik esnek mekanizmaya uyarlama çalışması deneysel ve teorik olarak incelenmiştir. Çalışma esnek mekanizmaların bașlıca avantajlarını ortaya çıarmak için hareketini sağlayan dört çubuk mekanizması, model uçak üzerindeki kisitlara göre boyutlandırılmıștır. Çalışma sonucunda, İHA'ya ait flap mekanizmasında kullanılan ve 12 parçadan olușan geleneksel mekanizma yerine eşleniği olan ve tek parçadan oluşan mekanizma tasarımı yapılmıştır. Esnek mekanizmaların analizlerinin gerçekleştirilmesinde eşlenik rijit cisim yöntemi kullanılarak sistem modellenmiștir. Sonuçlar göstermiștir ki esnek flap mekanizmalarının çalışmasında geleneksel rijit gövdeli mekanizmalara göre daha büyük tahrik torku gerekmektedir. Bu durum, esnek mekanizmaların avantajlarının yanında gerekli motor gücünü arttırmaları ve bu sebeple motor ebatlarının büyümesi bir diğer önemli dezavantajlarıdır. 
DEÜ FMD 23(69), 951-960, 2021

Esnek mekanizmanın yorulma davranıșını test edebilmek için dört çubuk mekanizması tasarlanıp üç boyutlu yazıcıda Semiflex filament kullanılarak üretilmiștir. Bu malzeme, yazarların araştırmalarına göre esnek flap mekanizmasında kullanılması ve yorulma testi çalışması literatürde ilktir. Semiflex filament kullanarak üretilen esnek mekanizmanın ömür testi sonucunda 717727 çevrim sayısına ulaşılmıştır. Çoğu mühendislik uygulamalarında olduğu gibi, esnek flap mekanizmasının da bir milyon ömüre ulaşması hedeflenmiştir ve mevcut çalışmada bu hedefin yaklaşık \% 71.8'ine ulaşılmıştır. Gelecek çalışmalarda yapılacak geometri optimizasyonları neticesinde bir milyon çevrime ulaşılması hedeflenmiştir.

Yapılan bu çalıșma, eklemeli imalat yöntemiyle üretilen esnek mekanizmaların havacılık uygulamasında kullanılabilirliği hakkında fikir vermektedir. Çalıșmanın ayrıca, literatürde bu alanda yapılacak yeni çalıșmalara yol göstereceği ve referans olacağl düșünülmektedir. Bu çalıșmada yapılan modelin ardından ileriki çalışmada, kanadın çalışma koşullarında simüle edilmesi için rüzgâr tüneli tasarlanıp elde edilen değerler ile dayanıklılığı, çalışma şartı altında yorulma değerleri gibi veriler değerlendirilecektir.

\section{Teșekkür}

Bu çalıșma, TÜBITAK 2209-A projesi kapsamında gerçekleștirilmiştir. Desteklerinden ötürü TÜBİTAK'a teșekkürlerimizi iletiyoruz. Değerli desteklerinden dolayı sayın Prof.Dr. Osman KOPMAZ’a teșekkür ederiz.

\section{Kaynakça}

[1] Çalık, B., 2014. Esnek Uzaysal Mekanizmaların Tasarımı ve Sonlu Elemanlar Yöntemi ile Analizi. Hacettepe Üniversitesi. Fen Bilimleri Enstitüsü. 162s. Ankara.

[2] Howell, L. L. $2013 . \quad$ Handbook of Compliant Mechanism. Wiley. 342s.

[3] Howell, L. L., Mitha, A. 1994. A Method for the Design of Compliant Mechanisms with Small-Length Flexural Pivot. Journal of Mechanical Design. 116(1): 280-290 (11 pages) DOI $10.1115 / 1.2919359$

[4] Anonim 2020 https://app.patentinspiration.com/\#report/4152e ea21734/filter. (Erisim Tarihi: 14.11.2020)

[5] J.P. Khatait, S. Mukherjee, B. Seth. 2006. Compliant design for flapping mechanism: A Minimum torque approach. Mechanism and Machine Theory. Volume 41 Issue $1 . \quad$ Pages 3-16. DOI: 10.1016/j.mechmachtheory.2005.06.002

[6] Kota S., Osborn R., Ervin G. Maric D. 2009. Mission Adaptive Compliant Wing - Design, Fabrication and Flight Test. RTO The Applied Vehicle Technology
Panel (AVT) and the Systems. 1-20. DOI: RTO-MPAVT168

[7] Nelson T.G., Avila A., Howell L.L., Herder J.L., Machekposhti D.F. 2019. Origami- inspired Sacrificial -Joints for Folding Compliant Mechanisms. Mechanism and Machine Theory. Volume $140.194-210.1$ DOI: 10.1016/j.mechmachtheory.2019.05.023

[8] Erkaya S., Uzmay İ. 2014. Modeling and Simulation of Joint Celarance Effects on Mechanisms Having Rigid and Flexible Links. Journal of Mechaniscal Science and Technology. 28 (8) 2979-2986. DOI: 10.1007/s12206-014-0705-2

[9] Gerdes J.W., Cellon K.C., Bruck H.A., Gupta S.K. 2013. Characterization of the Mechanics of Compliant Wing Designs for Flapping-Wing Miniature Air Vehicles. Experimental Mechanics. 53, pages15611571. DOI: $10.1007 / \mathrm{s} 11340-013-9779-5$

[10] Erkaya Ş., Ulus Ş., Doğan S. 2015. Klasik ve Esnek Bağlantılı Mekanizmalarda Eklem Boşluğu Etkisinin Nümerik ve Deneysel İncelenmesi. Selçuk Universitesi. Fen Bilimleri Enstitüsü. 342s.

[11] Ding Y., Lai Lei-Jie. 2019. Static and Dynamic Analysis of Flexure based Compliant Mechanism by Matrix Displacement Method. 2019 IEEE 5th International Conference on Mechatronics System and Robots (ICMSR). DOI: 10.1109/ICMSR.2019.8835474.

[12] Yue -Qing Y., Zhang N. 2019. Dynamic Modeling and Performance of Compliant Mechanisms -with Inflection Beams. Mechanism and Machine Theory. Volume $\quad 135 . \quad 455-475 . \quad$ DOI: 10.1016/j.mechmachtheory.2019.01.010

[13] Shili L., Wenjie G., Shujun L. 2008. Optimal Design of Compliant Trailing Edge for Shape Changing. Chinese Jornal of Auronautics. 21-2. 187-192. DOI: 10.1016/S1000-9361(08)60024-2

[14] Cai G., Lum K., Chen B., Lee T. 2010. A Brief Overview on Miniature Fixed-Wing Unmanned Aerial Vehicles. 2010 8th IEEE International Conference on Control and Automation Xiamen, China, June 9-11, 2010. DOI: 10.1109/ICCA.2010.5524453

[15] Dessalegn A., Yihun Y., Fernandes J., Lankarani H.. 2016. Effect of Variation of Link Lengths and Stiffness on the Gearing Ratio of a Four Bar Mechanism with Application to Aircraft Trim Tabs. ASME 2015 International Design Engineering Technical Conferences and Computers and Information in Engineering Conference. DOI: 10.1115/DETC2015-46054

[16] F. Freudenstein, 1954. An analytical approach to the design of four-link mechanism, Trans. ASME 76 483-492.

[17] Tanikella N.G., Wittbrodt B.,Pearce J.M.. 2017. Tensile strength of commercial polymer materials for fused filament fabrication 3D printing. Additive Manufacturing Volume 15, May 2017, Pages 40-47. DOI: 10.1016/j.addma.2017.03.005 
DEÜ FMD 23(69), 951-960, 2021

\section{Ekler}

Freudeinstein denklemi;

$l_{2} \cos \theta_{21}+l_{3} \cos \theta_{31}-l_{1}-l_{4} \cos \theta_{41}=0$

(E1)

$l_{2} \sin \theta_{21}+l_{3} \sin \theta_{31}-l_{4} \sin \theta_{41}=0$

(E2)

$l_{3} \cos \theta_{31}=-l_{2} \cos \theta_{21}+l_{1}+l_{4} \cos \theta_{41}$

(E3)

$l_{3} \sin \theta_{31}=-l_{2} \sin \theta_{21}+$

$l_{4} \sin \theta_{41}$

Bu iki denklemin çözümünden mekanizmaya ait parametrelerden ikisi diğerlerinin cinsinden yazllabilir.

$k_{1}\left(\theta_{21}\right) \sin \theta_{41}+k_{2}\left(\theta_{21}\right) \cos \theta_{41}+k_{3}\left(\theta_{21}\right)$

(E5)

$k_{1}\left(\theta_{21}\right)=$

$-2 l_{2} l_{4} \sin \theta_{21}$

(E6)

$k_{2}\left(\theta_{21}\right)=2 l_{4}\left(l_{1}-\right.$

$\left.l_{2} \cos \theta_{21}\right)$

$k_{3}\left(\theta_{21}\right)=l_{1}{ }^{2}+l_{2}{ }^{2}-l_{3}{ }^{2}+l_{4}{ }^{2}-$

$2 l_{1} l_{2} \cos \theta_{21}$

(E8)

$\mathrm{Bu}$ denklemler literatürde Freudenstein Denklemleri olarak bilinir.

$t=\frac{\tan \theta_{41}}{2}$

$\sin \theta_{41}=\frac{2 t}{1+t^{2}}$

$\cos \theta_{41}=\frac{1-t^{2}}{1+t^{2}}$

(E11)

$\left(k_{3}-k_{2}\right) t^{2}+\left(2 k_{1}\right) t+\left(k_{3}+k_{2}\right)=$

0

$t=$

$\frac{-k_{1} \pm \sqrt{{k_{1}}^{2}+{k_{2}}^{2}-k_{3}{ }^{2}}}{k_{3}-k_{2}}$

(E13)
Hız Analizi:

$\theta_{21}=\theta, \theta_{31}=\alpha$ ve $\theta_{41}=\varphi$ olduğu kabul edilir ise;

$$
\begin{gathered}
{\left[\begin{array}{ccc}
l_{1} \sin \theta & l_{2} \sin \alpha & -l_{3} \sin \varphi \\
-l_{1} \cos \theta & -l_{2} \cos \alpha & l_{3} \cos \varphi
\end{array}\right]\left[\begin{array}{c}
\dot{\theta} \\
\dot{\alpha} \\
\dot{\varphi}
\end{array}\right]=\left[\begin{array}{l}
0 \\
0
\end{array}\right]} \\
{\left[\begin{array}{cc}
l_{2} \sin \alpha & -l_{3} \sin \varphi \\
-l_{2} \cos \alpha & l_{3} \cos \varphi
\end{array}\right]\left[\begin{array}{c}
\dot{\alpha} \\
\dot{\varphi}
\end{array}\right]=\left[\begin{array}{c}
-l_{1} \cos \theta \\
l_{1} \sin \theta
\end{array}\right] \dot{\theta}} \\
{\left[\begin{array}{l}
\dot{\alpha} \\
\dot{\varphi}
\end{array}\right]=\left[\begin{array}{l}
S_{1}(\theta, \alpha, \varphi) \\
S_{2}(\theta, \alpha, \varphi)
\end{array}\right] \dot{\theta}} \\
S_{1}(\theta, \alpha, \varphi)=\frac{l_{1} \sin (\varphi-\theta)}{l_{2} \sin (\alpha-\varphi)} \\
S_{2}(\theta, \alpha, \varphi)=\frac{l_{1} \sin (\alpha-\theta)}{l_{3} \sin (\alpha-\varphi)}
\end{gathered}
$$

Lagrangian formülasyonunda, tüm sistemin Lagrange, toplam kinetik enerji ve toplam potansiyel enerji farkı olarak tarafindan tanımlanır. Sistemin toplam kinetik enerjisini şu şekilde belirleriz:

$$
\begin{array}{r}
T=\frac{1}{2}\left(m_{1}\left\|V_{C 1}\right\|^{2}+I_{1} \dot{\theta}^{2}\right)+\frac{1}{2}\left(m_{2}\left\|V_{C 2}\right\|^{2}+\right. \\
\left.I_{2} \dot{\alpha}^{2}\right)+\frac{1}{2}\left(m_{3}\left\|V_{C 3}\right\|^{2}+I_{3} \dot{\varphi}^{2}\right) \quad(\mathrm{E} 19)
\end{array}
$$

burada

$$
\left\|V_{C 1}\right\|^{2}=l_{c 1}^{2} \dot{\theta}^{2}
$$

$\left\|V_{C 2}\right\|^{2}=l_{1}{ }^{2} \dot{\theta}^{2}+l_{c 2}{ }^{2} \dot{\alpha}^{2}+2 l_{1} l_{c 2} \cos (\theta-\alpha) \dot{\theta} \dot{\alpha}$

$$
\begin{gathered}
\left\|V_{C 3}\right\|^{2}=l_{c 3}^{2} \dot{\varphi}^{2} \\
V=m_{1} g y_{c 1}+m_{2} g y_{c 2}+m_{3} g y_{c 3} \\
y_{c 1}=l_{c 1} \sin \theta \\
y_{c 2}=l_{1} \sin \theta+l_{c 2} \sin \alpha \\
y_{c 3}=l_{c 3} \sin \varphi
\end{gathered}
$$

Son olarak, tüm sistemin Lagrange yazılırsa:

$$
\begin{gathered}
L=T-V \\
L(\theta, \alpha, \varphi, \dot{\theta}, \dot{\alpha}, \dot{\varphi})=J_{1} \dot{\theta}^{2}+J_{2} \dot{\alpha}^{2}+J_{3} \dot{\varphi}^{2}+ \\
P_{1} C_{1}(\theta, \alpha) \dot{\theta} \dot{\alpha}+G(\theta, \alpha, \varphi) \\
J_{1}=\frac{1}{2}\left(m_{1} l_{c 1}{ }^{2}+I_{1}+m_{2} l_{1}{ }^{2}\right)
\end{gathered}
$$




$$
\begin{aligned}
& J_{2}=\frac{1}{2}\left(m_{2} l_{c 2}^{2}+I_{2}\right) \\
& J_{3}=\frac{1}{2}\left(m_{3} l_{c 3}{ }^{2}+I_{3}\right) \\
& P_{1}=m_{2} l_{1} l_{c 2} \\
& C_{1}(\theta, \alpha)=\cos (\theta-\alpha) \\
& G(\theta, \alpha, \varphi)=\left(-m_{1} g l_{c 1}-m_{2} g l_{1}\right) \sin \theta- \\
& m_{2} g l_{c 2} \sin \alpha-m_{3} g l_{c 3} \sin \varphi
\end{aligned}
$$

(E35)

Hareketin denklemi;

$\frac{d}{d t}\left(\frac{\partial L}{\partial \dot{\theta}}\right)-\frac{\partial L}{\partial \theta}=\tau_{\theta}$

olarak ifade edilir.

Hareketin genel dinamik denklemi yazılırsa;

$2\left[J_{1}+J_{2} S_{1}^{2}+J_{3} S_{2}^{2}+P_{1} C_{1} S_{1}\right] \ddot{\theta}+\left[2 J_{2} S_{1}\left(\frac{\partial S_{1}}{\partial \theta}+\right.\right.$

$\left.S_{1} \frac{\partial S_{1}}{\partial \alpha}+S_{2} \frac{\partial S_{1}}{\partial \varphi}\right)+2 J_{3} S_{2}\left(\frac{\partial S_{2}}{\partial \theta}+S_{1} \frac{\partial S_{2}}{\partial \alpha}+S_{2} \frac{\partial S_{2}}{\partial \varphi}\right)+$

$P_{1}\left(C_{1}\left(\frac{\partial S_{1}}{\partial \theta}+S_{1} \frac{\partial S_{1}}{\partial \alpha}+S_{2} \frac{\partial S_{1}}{\partial \varphi}\right)+S_{1}\left(\frac{\partial C_{1}}{\partial \theta}+\right.\right.$

$\left.\left.\left.S_{1} \frac{\partial C_{1}}{\partial \alpha}\right)\right)\right] \dot{\theta}-\frac{\partial G}{\partial \theta}-S_{1} \frac{\partial G}{\partial \alpha}-S_{2} \frac{\partial G}{\partial \varphi}=\tau_{\theta}$

(E37)

Eşlenik rijit cisim modelinde, burulma yaylarının katılıkları esnek bölgenin eğilmeye karşı direnci ile tarif edilebilmektedir. Kesme kuvveti etkisindeki şekil değişikliği ihmal edilmiştir.

$K=\frac{M_{e}}{\theta_{e}}=\frac{M_{e}}{\frac{M_{e} l_{k}}{E I_{k}}}=\frac{E I_{k}}{l_{k}}$

(E38) 